\title{
Virtual Medical Spanish Education at the Corazón of Hispanic/Latinx Health During COVID-19
}

\author{
Pilar Ortega ${ }^{1}$ (I) $\cdot$ Tiffany M. Shin ${ }^{2} \cdot$ Cristina Pérez-Cordón $^{3} \cdot$ Glenn A. Martínez ${ }^{4}$ \\ Published online: 19 August 2020 \\ (C) International Association of Medical Science Educators 2020
}

\section{Introduction}

Hispanic/Latinx health inequities have been exposed in the context of the coronavirus disease 2019 (COVID-19) pandemic. Existing health system deficiencies are at the heart and core — el corazón — of the health inequities being magnified during the current public health crisis for racial, ethnic, and linguistic minorities $[1,2]$. Among the most important factors that influence whether health information is understood and whether individuals can access care is language. Individuals with limited English proficiency (LEP) have improved health outcomes when they experience languageconcordant health care - that is, when their clinician speaks their language [3].

The lack of medical interpreter availability and increased difficulties with in-person access to care during the COVID19 health crisis have further complicated health care for linguistic minorities [4]. Cities such as New York, Boston, and Chicago are increasingly reporting large clusters of infection rates and disproportionately high death rates in Hispanic/ Latinx patients [5-7]. Rural Hispanic/Latinx groups are also at elevated risk given their significant representation in meat and poultry packing plants throughout the Midwest [8]. Some of the health system deficiencies that may result in a disproportionate impact of COVID-19 on language minority

Pilar Ortega

POrtega1@uic.edu

1 Departments of Emergency Medicine and Medical Education, University of Illinois College of Medicine, $808 \mathrm{~S}$. Wood Street, MC 591, Chicago, IL 60612, USA

2 Department of Pediatrics, Wake Forest School of Medicine, Winston-Salem, NC, USA

3 Language and Communication Training Unit, United Nations Headquarters, New York, NY, USA

4 Department of Spanish and Portuguese, Ohio State University, Columbus, OH, USA communities include a paucity of data regarding patient language and ethnicity, limited availability of languageappropriate services, and the lack of language-concordant health-care professionals [9].

Medical Spanish education has been proposed as a strategy to increase the language-concordant physician workforce [9-11]. Although many medical schools provide opportunities for students to enhance language skills such as medical Spanish [12], the COVID-19 pandemic also has affected the landscape of medical education, causing medical schools to seek virtual educational options for students [13]. Existing experiences in which students might have gained medical Spanish skills or clinical exposure to minority communities, such as clinical clerkships, away electives, study-abroad opportunities, and service-learning experiences, have in many cases been canceled or postponed in light of pandemic safety restrictions. Despite these restrictions, virtual learning platforms may present a new opportunity to effectively teach communication skills to care for linguistic minority populations.

\section{Virtual Medical Spanish Education and Population Health}

Building a professionally multilingual physician workforce through medical Spanish courses can address the languageconcordant physician deficit that affects a growing number of communities in the USA [14]. According to the most recent population estimates, the USA is home to 56.6 million individuals who identify as Hispanic/Latinx, representing 17.6\% of the population and constituting the largest and fastestgrowing racial or ethnic minority in the USA [15]. Moreover, 40 million US residents (13.3\% of the population) report speaking Spanish at home, and $42.6 \%$ of Hispanics who speak Spanish at home report speaking English less than very well [15]. The number of Spanish speakers in the USA represents a 131.2\% increase between 1990 and 2015 [15], 
making the USA the country with the second most Spanish speakers in the world (after Mexico) [16]. This trend is expected to continue, exacerbating unmet challenges to health systems and clinicians who, despite legal requirements [17] and guidelines to provide linguistically and culturally appropriate services to all patients [18], may be unprepared to do so, particularly during patient surges such as the COVID-19 pandemic.

Existing data shows that a majority of medical students53.2\% according to 2013 Electronic Residency Application System data - have some pre-existing Spanish skills [19], but many are being asked to use skills in patient care without appropriate training or confirmation of skills [20]. Moreover, a recent analysis of the alignment of non-English languagespeaking resident physicians and the LEP patient population geographic distribution demonstrates that Spanish is the US language with the lowest ratio of language-concordant resident physicians to patients [21]. Despite the public health need to increase the number of competent Spanish-speaking health professionals, the intrinsic complexities of medical Spanish education have resulted in barriers to medical Spanish course implementation. For example, lack of qualified educators and lack of time in the curriculum are two of the main reported barriers to offering medical Spanish education in medical schools [12]. Additionally, many schools' medical Spanish educational opportunities are student-led [12], a model that challenges long-term sustainability as well as curricular standardization. Importantly, concerns about unintentionally promoting medical student "false fluency" by imparting partial knowledge of medical Spanish without appropriately teaching limitations and self-assessment skills may also be a reason why schools are reticent to provide formal medical Spanish education [22].

Virtual access to medical Spanish programs can contribute to the democratization of knowledge by bridging previously identified physical and geographic barriers to medical Spanish education since educators need not be locally situated. Scholars in Spanish language pedagogy have made a compelling case that the appropriate use of technology can increase contact with the target language, address the variety of content interests that learners bring to language learning, and augment exposure to comprehensible input [23]. A thoughtful approach to virtual medical Spanish education may serve as an effective strategy to teach patient-centered communication skills for a linguistically vulnerable and growing patient population, particularly in schools in which it was not previously accessible or available. For example, some areas of the USA with the highest growth of the Hispanic/Latinx population are rural areas. North Dakota, West Virginia, and South Dakota are the three states with the highest immigrant population growth between 2010 and 2016 with 48\%, 41\%, and 39\% immigrant population growth, respectively, the majority of whom identify as Hispanic/Latinx [24]. At least half of the US immigrant population has LEP [25], although this may represent an underestimate due to difficulties in data capture for populations with language needs besides English [9, 14]. Medical school programs located in rural environments may experience an influx of patients with LEP due to immigrant population growth in rural communities, but their curricula and onsite faculty may not be prepared to provide language skills education such as medical Spanish courses. Additionally, considering pandemic restrictions suspending or postponing student in-person clinical experiences, opportunities to learn clinical and interpersonal skills through virtual strategies now are being sought widely and actively by medical schools both in rural and urban locations. Medical schools should take advantage of the current need to adjust curricula to virtual environments as an opportunity to also ensure that the educational content equitably addresses the linguistic and cultural communication needs of the US patient population. Given population trends, this would require intentional inclusion of communication skills with linguistic minority communities, particularly Spanish speakers.

Furthermore, it is critical to acknowledge that the challenge of communication with Spanish-speaking patients and other communities with LEP should not be addressed by medical students and physicians alone but also should involve other health professions and incorporate the perspectives of language experts. The more flexible online environment may facilitate medical Spanish collaboration among institutions and disciplines, and across health professions programs. For example, language educators and clinician experts have been called upon to collaborate in the development of medical Spanish educational standards, but their work is often unintentionally siloed in their respective departments [26]. Additionally, a virtual classroom in which students from various health programs, such as Medicine, Pharmacy, Nursing, Physical Therapy, Dentistry, and others, could collaborate to learn medical Spanish has never been published but could enable medical Spanish programs to more widely address the need for a linguistically and culturally prepared healthcare workforce.

\section{Language Skills and Virtual Learning Environments}

To understand how a medical Spanish course can be transformed into a high-quality virtual educational opportunity, the overall purpose, specific learning objectives, and assessment methods of such a course must be clearly defined. Historically, medical Spanish courses have lacked consistent curricular structure or objectives, resulting in many variations of course content, teaching activities, student Spanish proficiency pre-requisites, and learner objectives [12, 27, 28]. Medical Spanish in medical school settings has been defined 
by expert consensus as "the use of Spanish in the practice of medicine for communication with patients" [27].

A standardized list of five core learner competencies for medical Spanish students in medical school have been proposed and include (1) medical interviewing skills, (2) comprehension of the patient story, (3) patient-centered discussion of the assessment or diagnoses, (4) patient-centered discussion of the plan of care, and (5) self-assessment of confidence and limitations [27]. The fifth competency is a progressive lifelong learning goal for students to continually reassess strengths and weaknesses in communication skills with linguistic minority patients and has also been referred to as global linguistic competency [28]. Within the patient-centered learning objectives, medical Spanish courses are tasked not only to teach the linguistic aspects of communication but also to address the learner's cultural humility and cultural competency in order to understand the Spanish-speaking patient's sociocultural context and health communication needs [29, 30].

Teaching these communication skills goes far beyond teaching a vocabulary or terminology list or correcting grammar; in fact, while these activities form part of the background content necessary to teaching medical Spanish, experts recommend that medical Spanish courses focus on the patientcentered communication rather than on the technical medical vocabulary [31]. Synchronous, asynchronous, and blended synchronous/asynchronous strategies can be applied to virtual teaching and learning of medical Spanish skills. For example, elements of grammar and vocabulary-focused education may be effectively taught through asynchronous learning methods such as vocabulary and grammar exercises or games that aid memorization and support other cognitive processes that reinforce learning in general and language learning in particular [32].

Patient-centered communication skills, however, must be taught, observed, and practiced using more interactive modalities. For instance, a flipped-classroom approach is a type of blended learning in which students are introduced to content through pre-recorded videos and texts (individual learning space), and face-to-face classroom time using video communication solutions is dedicated to interactive activities that require personal engagement such as dialogues, debates, or presentations (group learning space). This approach can be an effective way for students to review and learn material in preparation for class, which would be dedicated to applied language use and faculty-guided reinforcement. A digital voiceboard, through which students can record themselves speaking in response to prompts, is an asynchronous strategy that has been shown to provide students an opportunity to both practice and reflect on responses to patient queries during the medical interview [33]. Table 1 summarizes our recommended pedagogical practices and examples for implementation in virtual medical Spanish courses, as well as how these practices align with medical Spanish course competencies, learning objectives, and expected performance outcomes [27].

Transforming medical Spanish courses from in-person to virtual learning platforms need not require recreating the curriculum for schools with pre-existing formal medical Spanish courses but rather adapting the teaching methods and practices to the virtual environment. Adapting courses for virtual education may present a useful opportunity to revisit the course objectives, to maximize the productivity of face-to-face sessions through high-yield clinically relevant interactive methods, and to address some potentially deficient components of the program. For example, the assessment of medical Spanish linguistically and culturally appropriate communication skills is a critical element of medical Spanish education, yet one that has been lacking in a majority of reported medical Spanish courses [12]. For example, arranging virtual role-play pairings by level of proficiency, providing real-time constructive feedback on performance, fostering peer-to-peer reviews and assessments, and guiding students on how to effectively self-reflect on their strengths and limitations can be important ways to continually assess students' performance, confidence, and skill levels. This learner-centered assessment method should ideally not only evaluate but also lead to the progressive improvement of the students' language skills and cultural competence, and to the gradual growth in student confidence commensurate with skills acquisition. A continuous assessment through role-play activities and other interactive classroom experiences may better contribute to this goal than a single final exam as the only learner assessment methodology.

Moreover, standardized patient (SP) encounters, which are the recommended approach to assessing student skills at the end of a medical Spanish course [28], can be conducted through virtual solutions. The simulated telehealth encounter can be useful for assessing medical student performance in a setting that reflects the realities of current access to care under pandemic circumstances. Telehealth communication presents particular challenges to clinicians and patients with LEP, since it may be more difficult to interpret gestures, display empathy, or address limited health literacy using video technology [34]. During the COVID-19 crisis, health systems are encountering barriers to the technological application of their prior language assistance staff, such as interpreters or patient advocates, to telehealth encounters [34, 35]. Further, patients with LEP have increased difficulty and decreased comfort with using technology to access health services [36]. As a result, using telehealth SP encounters as part of medical Spanish courses may not only be useful for assessing student performance of medical Spanish skills but may also serve to educate learners on strategies to communicate empathically and effectively 
Table 1 Virtual medical Spanish pedagogy and proposed examples for implementation

\begin{tabular}{|c|c|c|c|c|}
\hline $\begin{array}{l}\text { Pedagogical } \\
\text { practice }\end{array}$ & Example for implementation & $\begin{array}{l}\text { Target core } \\
\text { competency }\end{array}$ & Learning objectives & Expected performance outcomes \\
\hline $\begin{array}{l}\text { Flipped } \\
\text { classroom }\end{array}$ & $\begin{array}{l}\text { Pre-class assignments: Students } \\
\text { receive a video lecture, podcast, or } \\
\text { reading assignment to complete prior } \\
\text { to class. } \\
\text { Conversation sessions: Between class } \\
\text { virtual sessions, students are } \\
\text { assigned to participate in } \\
\text { pre-arranged small group virtual } \\
\text { meetings to foster conversation fo- } \\
\text { cused on specific health topics in } \\
\text { Spanish. } \\
\text { Self-study exercises: Students } \\
\text { independently complete vocabulary } \\
\text { and grammar exercises or games to } \\
\text { cognitively reinforce new } \\
\text { vocabulary or grammar through } \\
\text { workbooks or online software (e.g., } \\
\text { Quizlet or Anki). }\end{array}$ & $\begin{array}{l}\text { Competency 1: } \\
\text { Medical } \\
\text { interviewing } \\
\text { skills }\end{array}$ & $\begin{array}{l}\text { Demonstrate medical Spanish } \\
\text { knowledge regarding organ } \\
\text { systems, medical interviewing } \\
\text { questions, and physical } \\
\text { examination instructions }\end{array}$ & $\begin{array}{l}\text { Obtain an accurate complete } \\
\text { medical history } \\
\text { Engage and instruct the patient } \\
\text { in the physical examination }\end{array}$ \\
\hline $\begin{array}{c}\text { Break-out } \\
\text { rooms }\end{array}$ & $\begin{array}{l}\text { Small group discussions: Students are } \\
\text { assigned to break-out rooms in pairs } \\
\text { or small groups to conduct role plays } \\
\text { or discuss focused cases or prompts } \\
\text { regarding challenging topics (e.g., } \\
\text { sociocultural barriers). The instructor } \\
\text { visits each room to provide guidance } \\
\text { as needed. }\end{array}$ & $\begin{array}{l}\text { Competency 2: } \\
\text { Comprehension } \\
\text { of the patient } \\
\text { story }\end{array}$ & $\begin{array}{l}\text { Demonstrate medical Spanish } \\
\text { knowledge regarding common } \\
\text { disease entities } \\
\text { Comprehend health information } \\
\text { provided in Spanish } \\
\text { Recognize and discuss cultural } \\
\text { issues in the care of } \\
\text { Spanish-speaking patients }\end{array}$ & $\begin{array}{l}\text { Conduct a complete medical } \\
\text { encounter in Spanish, } \\
\text { including inviting the patient } \\
\text { to raise questions or concerns. } \\
\text { Document the visit accurately to } \\
\text { demonstrate comprehension } \\
\text { of the patient interview and } \\
\text { systems-based practice }\end{array}$ \\
\hline
\end{tabular}

Skills practice: Break-out rooms are created, each with a particular medical Spanish "skill" to be practiced (e.g., discussing bad news). One student or teaching assistant, if available, is assigned to lead a particular skill. The other students rotate through each room at pre-determined intervals.

Clinical Student-led role play: A student must role-play prepare a case related to the class activities topic and will play the role of the patient while another student is tasked as the clinician interviewing the patient.

Digital recordings: Students are assigned to prepare a video or audio recording in response to a video/audio prompt or a patient scenario as oral/aural practice using digital voiceboards. The faculty reviews and provides constructive feedback.

Self-reflection Guided self-assessment at key activities intervals: Students are guided on how to self-reflect on their personal strengths and limitations in medical Spanish at various points throughout the course, such as pre-course, mid-course, and end-course.

Post-activity guided self-reflection: Students respond to a self-reflection prompt following a role play or performance assessment activity, such as a standardized patient encounter.

Competency 3: Demonstrate patient-centered exPatient-centered planation of medical diagnoses/discussion of the assessment.

assessment or Demonstrate patient-centered exdiagnoses planation of treatment/evaluation Competency 4: plan.

Patient-centered discussion of the plan of care

Competency 5: Self-assessment of confidence and limitations
Accurately and progressively self-assess confidence and limitations in medical Spanish Identify when and how to work with a medical interpreter
Orally explain findings of the medical evaluation and plan to the patient, adjusted for cultural, emotional, and literacy needs

Assess patient comprehension of the information provided and address knowledge gaps or concerns
Seek a medical interpreter if/when limitations are reached

Effectively work with a medical interpreter 
Table 1 (continued)

\begin{tabular}{|c|c|c|c|c|}
\hline $\begin{array}{l}\text { Pedagogical } \\
\text { practice }\end{array}$ & Example for implementation & $\begin{array}{l}\text { Target core } \\
\text { competency }\end{array}$ & Learning objectives & Expected performance outcomes \\
\hline $\begin{array}{l}\text { Performance } \\
\text { assessment }\end{array}$ & $\begin{array}{l}\text { Progressive course feedback: } \\
\text { Real-time feedback is provided dur- } \\
\text { ing synchronous classroom interac- } \\
\text { tive activities such as role plays; } \\
\text { feedback may be provided by the } \\
\text { faculty member as well as } \\
\text { peer-to-peer feedback guided by } \\
\text { faculty. } \\
\text { Simulated case post-assessments: A } \\
\text { simulated telehealth encounter is } \\
\text { conducted on a virtual platform to } \\
\text { assess student skills, and student } \\
\text { receives feedback from standardized } \\
\text { patient and faculty member. }\end{array}$ & Competencies 1-5 & $\begin{array}{l}\text { Evaluate the extent to which the } \\
\text { listed course learning objectives } \\
\text { and performance objectives have } \\
\text { been met for each learner. }\end{array}$ & $\begin{array}{l}\text { Improve the learner's ability to } \\
\text { successfully communicate } \\
\text { with Spanish-speaking pa- } \\
\text { tients } \\
\text { Better serve Spanish-speaking } \\
\text { patients by identifying and } \\
\text { addressing communicative } \\
\text { gaps and limitations }\end{array}$ \\
\hline
\end{tabular}

with Spanish-speaking patients using video technology. Such an educational and assessment strategy for medical students may enhance their preparedness to provide competent language-concordant telehealth care for vulnerable populations.

\section{Conclusion}

Language is an important factor in the health inequities experienced by linguistic minority groups and currently magnified by the COVID-19 pandemic. Addressing language needs is at the core of health equity for linguistic minorities, and improving virtual access to high-quality medical Spanish education is an important strategy to prepare medical students and other health professionals to care for vulnerable communities during the current pandemic and beyond. Next steps in enhancing virtual medical Spanish education and assessment should include an evaluation of medical school strategies and methodologies in transforming current medical Spanish courses into virtual learning environments, collaboration among medical Spanish faculty to evaluate and share virtual learning resources, and the development of a national repository of standardized virtual SP encounters and assessment methodology for evaluation and eventual certification of medical student and physician medical Spanish skills.

\section{Code Availability Not applicable.}

Author Contributions The first draft of the manuscript was written by Pilar Ortega, MD, and all of the authors commented on previous versions of the manuscript. All of the authors read and approved the final manuscript.
Data Availability Not applicable.

\section{Compliance with Ethical Standards}

Conflict of interest P. Ortega receives author royalties from Saunders (an imprint of Elsevier) for a textbook.

\section{References}

1. Ross J, Díaz CM, Starrels JL. The disproportionate burden of COVID-19 for immigrants in the Bronx, New York. JAMA Intern Med. Published online May 08. 2020. https://doi.org/10. 1001/jamainternmed.2020.2131.

2. Webb Hooper M, Nápoles AM, Pérez-Stable EJ. COVID-19 and racial/ethnic disparities. JAMA. Published online May 11. 2020. https://doi.org/10.1001/jama.2020.8598.

3. Diamond L, Izquierdo K, Canfield D, Matsoukas K, Gany F. A systematic review of the impact of patient-physician non-English language concordance on quality of care and outcomes. J Gen Intern Med. 2019;34(8):1591-606. https://doi.org/10.1007/ s11606-019-04847-5.

4. Goldberg E. When coronavirus care gets lost in translation. New York Times. April 17, 2020. https://www.nytimes.com/2020/04/ 17/health/covid-coronavirus-medical-translators.html - click= https://t.co/GKeBeNA5XQ. Accessed 14 May 2020.

5. Della Cava, M. Latinos disproportionately dying, losing jobs because of the coronavirus: 'Something has to change.' USA Today. April 19, 2020. https://www.usatoday.com/story/news/nation/ 2020/04/18/coronavirus-latinos-disproportionately-dying-losingjobs/5149044002/. Accessed 14 May 2020.

6. Aguilera, J. Coronavirus patients who don't speak English could end up 'unable to communicate in their last moments of life.' Time. April 13, 2020. https://time.com/5816932/coronavirus-medicalinterpreters/. Accessed 14 May 2020.

7. Illinois Department of Public Health, COVID-19 statistics. Updated May 7, 2020. https://www.dph.illinois.gov/covid19/covid19statistics. Accessed 14 May 2020. 
8. García, JE. Trump orders meat and poultry plants to remain open despite growing threat of COVID-19 infections. Latino USA. April 29, 2020. https://www.latinousa.org/2020/04/29/trump-ordersmeat/. Accessed 16 May 2020.

9. Ortega P. Spanish language concordance in U.S. medical care: a multifaceted challenge and call to action. Acad Med. 2018;93(9): 1276-80. https://doi.org/10.1097/acm.0000000000002307.

10. Fernández A, Pérez-Stable EJ. ¿Doctor, habla español? Increasing the supply and quality of language-concordant physicians for Spanish-speaking patients. J Gen Intern Med. 2015;30(10):1394 6. https://doi.org/10.1007/s11606-015-3436-x.

11. Ortega P, Pérez N, Robles B, Turmelle Y, Acosta D. Teaching medical Spanish to improve population health: evidence for incorporating language education and assessment in U.S. medical schools. Health Equity. 2019;3(1):557-66. Published 2019 Nov 1. https://doi.org/10.1089/heq.2019.0028.

12. Morales R, Rodríguez L, Singh A, et al. National survey of medical Spanish curriculum in U.S. medical schools. J Gen Intern Med. 2015;30(10):1434-9. https://doi.org/10.1007/s11606-015-3309-3.

13. Rose S. Medical student education in the time of COVID-19. JAMA. Published online March 31. 2020. https://doi.org/10.1001/ jama.2020.5227.

14. García ME, Bindman AB, Coffman J. Language-concordant primary care physicians for a diverse population: the view from California. Health Equity. 2019;3(1):343-9. Published 2019 Jul 1. https://doi.org/10.1089/heq.2019.0035.

15. U.S. Census Bureau. Profile America facts for features: Hispanic heritage month 2016. Available at https://www.census.gov/content/ dam/Census/newsroom/facts-for-features/2016/cb16-ff16.pdf. Accessed 27 July 2020.

16. El español: una lengua viva. Informe del Instituto Cervantes, 2018. https://cvc.cervantes.es/lengua/espanol_lengua_viva/pdf/espanol_ lengua_viva_2018.pdf. Accessed 27 July 2020.

17. Improving access to services for persons with limited English proficiency. Executive Order 13166. Fed Regist. 2000;65:5011950122.9 Office of Minority Health, U.S. Department of Health and Human Services.

18. National standards for culturally and linguistically appropriate services in health and health care: a blueprint for advancing and sustaining CLAS - policy and practice. https://www.thinkculturalhealth. hhs.gov/pdfs/EnhancedCLASStandardsBlueprint.pdf. Published April 2013. Accessed 27 July 2020.

19. Diamond L, Grbic D, Genoff M, Gonzalez J, Sharaf R, Mikesell C, et al. Non-English-language proficiency of applicants to US residency programs. JAMA. 2014;312(22):2405-7. https://doi.org/10. 1001/jama.2014.15444

20. Vela MB, Fritz C, Press VG, Girotti J. Medical students' experiences and perspectives on interpreting for LEP patients at two US medical schools. J Racial Ethn Health Disparities. 2016;3(2):2459. https://doi.org/10.1007/s40615-015-0134-7.

21. Diamond LC, Mujawar I, Vickstrom E, Garzon MG, Gany F. Supply and demand: association between non-English languagespeaking first year resident physicians and areas of need in the USA. [published online ahead of print, 2020 Jun 2]. J Gen Intern Med. 2020:2289-95. https://doi.org/10.1007/s11606-020-05935-7.

22. Diamond LC, Jacobs EA. Let's not contribute to disparities: the best methods for teaching clinicians how to overcome language barriers to health care. J Gen Intern Med. 2010;25 Suppl 2(Suppl 2):S189-93. https://doi.org/10.1007/s11606-009-1201-8.
23. Blake R. Brave New digital classroom: technology and foreign language learning. 2nd ed. Washington: Georgetown UP; 2013.

24. Batalova J, Alperin E. Immigrants in the U.S. states with the fastestgrowing foreign-born populations. https://www.migrationpolicy. org/article/immigrants-us-states-fastest-growing-foreign-bornpopulations\#CountriesOrigin. July 10, 2018. Accessed 14 May 2020.

25. Zong J, Batalova J. The limited English proficient population in the United States. Migration Policy Institute. July 8, 2015. http://www. migrationpolicy.org/article/limited-english-proficient-populationunited-states. Accessed 14 May 2020.

26. Hardin KJ, Hardin DM. Medical Spanish programs in the United States: a critical review of published studies and a proposal of best practices. Teach Learn Med. 2013;25(4):306-11. https://doi.org/10. 1080/10401334.2013.827974.

27. Ortega P, Diamond L, Alemán MA, Fatás-Cabeza J, Magaña D, Pazo V, et al. Medical Spanish standardization in U.S. medical schools: consensus statement from a multidisciplinary expert panel. Acad Med. 2020;95(1):22-31. https://doi.org/10.1097/acm. 0000000000002917.

28. Ortega P, Pérez N, Robles B, Turmelle Y, Acosta D. Strategies for teaching linguistic preparedness for physicians: medical Spanish and global linguistic competence in undergraduate medical education. Health Equity. 2019;3(1):312-8. Published 2019 Jul 1. https:// doi.org/10.1089/heq.2019.0029.

29. Dejbord-Sawan P. Beginning medical Spanish: oral proficiency and cultural humility. New York: Routledge; 2020.

30. Tervalon M, Murray-García J. Cultural humility versus cultural competence: a critical distinction in defining physician training outcomes in multicultural education. Journal of Health Care for the Poor and Underserved. 1998;9:117-25. https://doi.org/10.1353/ hpu.2010.0233.

31. Ortega P, Prada J. Words matter: Translanguaging in medical communication skills training. [published online ahead of print, 2020 May 19]. Perspect Med Educ. 2020. https://doi.org/10.1007/ s40037-020-00595-Z.

32. Miller M. Minds online: teaching effectively with technology. Cambridge: Harvard University Press; 2014.

33. Martínez G. Spanish in health care: policy, practice and pedagogy in Latino health. New York: Routledge; 2020.

34. Nouri S, Khoong EC, Lyles CR, Karliner L. Addressing equity in telemedicine for chronic disease management during the Covid-19 pandemic. NEJM Catal. 2020;1(3). https://doi.org/10.1056/CAT. 20.0123 .

35. Kaplan J. Hospitals have left many COVID-19 patients who don't speak English alone, confused, and without proper care. ProPublica. May 10, 2020. https://www.propublica.org/article/ hospitals-have-left-many-covid19-patients-who-dont-speakenglish-alone-confused-and-without-proper-care. Accessed 20 May 2020.

36. Mitchell UA, Chebli PG, Ruggiero L, Muramatsu N. The digital divide in health-related technology use: the significance of race/ethnicity. Gerontologist. 2018;59(1):6-14. https://doi.org/10. 1093/geront/gny138.

Publisher's Note Springer Nature remains neutral with regard to jurisdictional claims in published maps and institutional affiliations. 